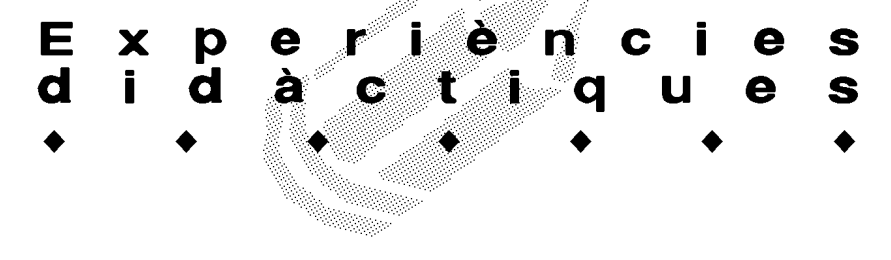

\title{
EL PRÀCTICUM II A LONDRES
}

\author{
Romina Pastor Bertomeu, Glòria Marín Martínez, Montse Margalef Borràs, Raquel Romero Gómez- \\ Pimpollo, M. Josep Margalef Valldepérez i Loida Gil Robles. Alumnes de tercer curs de l'Ensenyament de \\ Mestres, especialitat de Llengües Estrangeres. URV
}

El conveni signat entre la Facultat de Ciències de l'Educació i Psicologia i l'Instituto Español Vicente Cañada Blanch de Londres ha permès als alumnes de Llengües Estrangeres, realitzar la pràctica escolar de quasi tres mesos de durada a l'institut londinenc. Aquest és el segon any que els alumnes de $3 r$ curs tenen l'oportunitat de realitzar una estada d'aquesta mena a Anglaterra.

Aquest conveni millora substancialment el currículum de l'especialitat d'anglès, ja que possibilita que els alumnes ampliïn la seva formació acadèmica amb un coneixement pràctic no només d'un centre bilingüe, sinó tot l'enriquiment lingüístic i cultural que suposa viure immersos en aquell país durant quasi tres mesos.

La receptivitat mostrada per l'equip directiu de l'institut, representada pel seu director, Sr. Albert Vitrià, ha estat encomiable en tot moment. És d'agrair, especialment, la seva actitud en el sentit d'acceptar el màxim nombre possible dels nostres alumnes.

Segons la planificació general del Practicum II, els alumnes de $3 r$ curs tenen unes tutories prèvies a la realització de l'activitat, que en aquest cas es van augmentar a fi i efecte de facilitat tot tipus d'informació sobre l'institut i la ciutat de Londres.

Les tutories es van continuar fent, a través del correu electrònic, durant la seva estada a Anglaterra, i es van complementar amb una visita a l'institut per part dels tutors de la Facultat cap a la meitat del període de pràctiques.

S'ha pensat que seria especialment interessant que els mateixos alumnes donem la nostra visió de l'estada a Londres, amb l'objectiu d'animar els companys de futures promocions a realitzar la mateixa experiència que nosaltres hem viscut. És per això que a continuació es descriu aquesta experiència.

\section{Londres, un destí encertat?}

Marxar fora de casa un temps és una decisió que s'ha de valorar tant en els aspectes positius com en els negatius: família, feina, economia... Després de sospesar-ho tot, t'adones que tota l'experiència que pots assolir és tan enriquidora que val la pena llançar-t'hi. Quan t'has decidit, et vénen moltes preguntes al cap: On viuré? Em sabré comunicar prou bé?...
La millor opció és marxar tenint un allotjament provisional $i$ un cop allà buscar pis o habitació personalment a les agències i veure les diferents ofertes abans de decidir-te. També hi ha la possibilitat de viure amb una família posant-te, prèviament, en contacte amb l'escola per aconseguir algun contacte.

Una ciutat tan gran com Londres pot ser aclaparadora, i nosaltres com a grup així ho hem experimentat. Estar-hi sol pot resultar molt dur, per això és bo viure amb algun company de pràctiques per compartir qualsevol problema que pugui sorgir.

Si estàs acostumat a viatjar, trobes normal tot el que comporta viure en un país estranger i en una ciutat com Londres: gran, cosmopolita, multicultural i tan moderna que et pot arribar a menjar. Els primers dies cal que t'adaptis al seu ritme per sobreviure. Has de saber aprofitar l'estada i gaudir-ne al màxim, perquè només són tres mesos que de cop i volta ja han passat i et queda la sensació d'haver-te deixat coses per fer.

El nostre primer contacte amb Londres va ser una barreja de sorpresa i neguit. De cop ens trobàvem en una ciutat plena de gent de tot arreu, ens feia l'efecte d'estar dins d'un petit món dins del món. Miressis on miressis, veies autobusos vermells plens de gent, taxis negres a la recerca de nous clients, cotxes que circulaven per l'esquerra! Tot plegat una mica impactant per a la vista, però agradable per a la resta de sentits.

\section{L'escola. La primera impressió}

Un cop instal-lats, vam decidir visitar l'escola abans de començar les pràctiques per donar-nos a conèixer. La rebuda no va poder ser més bona. Es van interessar per tots i cadascun de nosaltres: si teníem lloc per viure, amb qui vivíem, on, etc. i ens van oferir la seva ajuda per a tot allò que necessitéssim. Ens van ensenyar el centre i vam quedar al.lucinats.

El "Vicente Cañada Blanch" és un antic convent de monges que manté la seva estructura original: un claustre preciós; l'antiga capelleta, convertida en sala de professors, i fins i tot l'església actual, aula polivalent. El pati és enorme i està provist d'una gran carpa per als dies de pluja. En general, un centre per on ve de gust passejar-te. 


\section{Exy}

Quan entres en una aula, el primer que et crida l'atenció és la varietat de nacionalitats que hi ha entre els nens. Cal tenir en compte que, tot i que la gran majoria són fills o néts d'espanyols, han nascut a Anglaterra. Aquesta canalla domina tant l'anglès com el castellà, són totalment bilingües.

Al principi espanta una mica la idea d'haver d'ensenyar anglès a alumnes que en saben més que tu. Però a poc a poc, t'adones que tenen les mateixes dificultats lingüístiques que la resta de nens de la seva edat, i que tu pots ajudar-los.

Per altra banda, també hi ha els nens que s'han traslladat a Londres fa relativament poc temps i que tenen adquirit el nivell d'anglès que correspon al currículm espanyol per a la seva edat, o els nens que són totalment anglesos i que tenen problemes amb el castellà. L'escola resol aquest problema mitjançant els suports que podríem comparar amb l'aula de reforç de les escoles d'aquí.

Un cop t'has acostumat als canvis, és quan realment comença la teva vida londinenca. Depèn d'on visquis, la jornada començarà més o menys aviat al matí. Agafes un autobús de color vermell o el "tube" per fer cap a l'escola. Les classes comencen a les 8'45 del matí. Es fa un descans entre les 10'40 i les 11'10. A les 12 els nens van a dinar i reprenen les classes a les 13'30 fins a les 15'20, que ja és hora de plegar.

Acabada la jornada escolar, molts de nosaltres aprofitàvem per anar a l'aula d'informàtica per posar-nos al dia de les notícies i enviar correus electrònics. Algunes vegades fèiem com els anglesos i anàvem a un pub a prendre una cerveseta abans de marxar cap a casa. El cap de setmana l'aprofitàvem per fer turisme o fer de cicerones de les múltiples visites que vam rebre.

\section{Les últimes setmanes a l'escola}

Les últimes setmanes van ser molt dures. Ja coneixíem els nens i ens havíem acostumat a l'ambient de l'escola. Cada cop que pensàvem que quedava menys, el cor se'ns encongia. A mesura que anava passant el temps n'hi havia que no veien l'hora de tornar cap a casa, mentre que d'altres es delien pensant en l'últim dia.

Vam dedicar molt temps preparant la unitat de programació que havíem de dur a terme cadascú de nosaltres. L'esforç va valer la pena i els alumnes van aprendre el que ens havíem proposat.

Cada vegada que miràvem els nens i pensàvem que ja quedaven poques setmanes per estar amb ells $i$ que segurament no els tornaríem a veure mai més, ens posàvem tristos i alhora ens motivàvem por donar-los tot el millor de nosaltres.

L'afecte va ser mutu, i quan ens vam acomiadar no podíem contenir les llàgrimes. L'última vegada que vam sortir per la porta de l'escola vam recordar tots els bons moments que hi havíem passat, tant amb els alumnes com amb la resta de professors.

\section{Una visita inesperada}

A mitjans de la nostra estada, vam rebre una visita dels nostres tutors, Julián de las Cuevas i Enric Anton. Però per gran sorpresa nostra també van venir la Marisa Garcia de Oteyza i la Dolors Roigé. Va ser una visita molt curta, però vam aprofitar molt el temps. Van venir a conèixer l'escola i també vam fer una mica de turisme. És curiós com pot canviar l'opinió que tens d'un professor quan el coneixes fora de l'aula. La veritat és que ens ho vam passar molt bé amb la seva companyia. Des d'aquí els volem agrair el detall que van tenir quan ens van venir a veure i l'inestimable suport que ens van donar en tot moment. Gràcies.

Costa molt tornar a casa després de viure tres mesos en una ciutat com Londres. Però no només era tornar a la rutina el que ens feia més mandra, sinó que havíem de plasmar en fulls tota la nostra experiència. És difícil expressar en paraules tot el que vam viure tant a l'escola com a fora, perquè en el nostre cas no pots separar una cosa de l'altra. Finalment aconsegueixes expressar per escrit tots els moments viscuts allà i t'adones que n'hi ha de dolents, però només els bons acaben perdurant per sempre.

\section{Conclusions}

L'experiència ha estat molt bona i enriquidora. Hem après moltes coses tant dels altres com de nosaltres mateixos. Com a persones i com a estudiants, hem interioritzat un recull d'experiències inoblidables.

La relació que teníem entre nosaltres ha canviat com de la nit al dia. És clar que ens coneixíem tots de veure'ns a classe o per la Facultat, però en aquests tres mesos que vam estar units com una família hem cultivat una amistat que esperem que duri per sempre.

Vam ser molt afortunats de tenir una família que des de casa ens donava suport en tot moment, tant de manera emocional com econòmica. No ens enganyem, viure tres mesos a Londres és una despesa econòmica molt gran, i a més si tenim en compte que no hem rebut cap ajut econòmic d'enlloc. Des d'aquí volem demanar que, de cara als propers anys, es contempli en algun pla de mobilitat el Pràcticum II de mestre a l'estranger.

Com a consells us podem dir: Aprofiteu l'estada a Londres per conèixer la ciutat al màxim. Informeu-vos de tots els esdeveniments que hi ha. Aneu al teatre (si sou entusiastes del teatre), no us perdeu els museus (són gratuïts) i el més important, xaleu al màxim! 